\title{
容器入り飲用海洋深層水の性状について
}

\author{
佐々木弘子*1 ・ 小堀千春*1 ・ 野口幸子*1 ・ 松澤睦子*2 ・ \\ 根岸由紀子*3・廣末トシ子*2・菅原龍幸*1 \\ $(* 1$ 聖徳大学人文学部， $* 2$ 女子栄養大学短期大学部， $* 3$ 女子栄養大学栄養学部 $)$

\section{Properties of bottled drinking deep sea water}

\author{
Hiroko Sasaki*1, Chiharu Kobori*1, Sachiko Noguchi*1, Mutsuko Matsuzawa*2, \\ Yukiko Negishi*3 ${ }^{* 3}$ Toshiko Hirosue*2, Tatsuyuki Sugahara*1 \\ ${ }^{* 1}$ Seitoku University, 550 Iwase, Matsudo-shi, Chiba, 271-8555 \\ ${ }^{*}$ Kagawa Nutrition University, 3-24-1 Komagome, Toshima, Tokyo, 154-8481 \\ *3Kagawa Nutrition University, 3-9-21 Chiyoda, Sakado-shi, Saitama, 350-0288 \\ *1 $\mathbf{7} 271-8555$ 千葉県松戸市岩瀬 550 \\ *2 于154-8481 東京都豊島区駒込 3-24-3 \\ *3 厂 350-0288 埼玉県坂戸市千代田 3-9-21
}

The general properties relating to the composition and hygienic properties of fourteen brands of bottled drinking deep sea water and one of deep sea water (source water) were investigated.

(1) Most of the brands of bottled drinking deep sea water were produced by a reverse osmosis system.

(2) Composition of bottled drinking deep sea water; Residues on evaporation 663 $\pm 592.2 \mathrm{ppm}$, hardness $344 \pm 360.3 \mathrm{ppm}$, free carbon dioxide $3.7 \pm 1.89 \mathrm{ppm}, \mathrm{pH}$ 4.8 alkalinity $8.9 \pm 9.28 \mathrm{ppm}, \mathrm{pH} 6.81 \pm 0.483$, consumption of $\mathrm{KMnO}_{4} 1.1 \pm 0.84 \mathrm{ppm}$.

Composition of source water; Residues on evaporation $42723 \mathrm{ppm}$, free carbon dioxide 7.4ppm, pH4.8 alkalinity $61.1 \mathrm{ppm}, \mathrm{pH} 7.4$, consumption of $\mathrm{KMnO}_{4} 199.6 \mathrm{ppm}$.

(3) Mineral contents of bottled drinking deep sea water; Na $43.7 \pm 29.21 \mathrm{ppm}$, $\mathrm{Mg} 83.3 \pm 87.42 \mathrm{ppm}, \mathrm{K} 10.5 \pm 17.00 \mathrm{ppm}, \mathrm{Ca} 14.7 \pm 17.88 \mathrm{ppm}, \mathrm{B} 13.7 \pm 13.92 \mathrm{ppm}, \mathrm{Li}$ $6.1 \pm 7.77 \mathrm{ppb}$, Al $1.3 \pm 1.30 \mathrm{ppb}$, Si $1.67 \pm 2.666 \mathrm{ppm}$, P $41.7 \pm 30.57 \mathrm{ppb}, \mathrm{V} 12.5 \pm$ $7.36 \mathrm{ppb}$, Cr $0.3 \pm 0.21 \mathrm{ppb}$, Mn $1.0 \pm 2.12 \mathrm{ppb}$, Fe $12.9 \pm 3.64 \mathrm{ppb}$, Ni $0.4 \pm 0.35 \mathrm{ppb}$, $\mathrm{Cu} 0.95 \pm 0.76 \mathrm{ppb}, \mathrm{Zn} 1502.6 \pm 4311.9 \mathrm{ppm}, \mathrm{Ge} 1.2 \pm 0.72 \mathrm{ppb}$, Se $2.7 \pm 3.81 \mathrm{ppb}, \mathrm{Rb}$ $3.6 \pm 4.82 \mathrm{ppb}$, Mo $0.7 \pm 0.71 \mathrm{ppb}$.

(4) Inorganic anions in bottled drinking deep sea water; F 5.4 $\pm 8.56 \mathrm{ppm}(\mathrm{n}=9)$, $\mathrm{Cl} 252.2 \pm 207.55 \mathrm{ppm}(\mathrm{n}=14), \mathrm{Br} 3.7 \pm 1.19 \mathrm{ppm}(\mathrm{n}=4), \mathrm{NO}_{3} 3.8 \pm 6.28 \mathrm{ppm}(\mathrm{n}=7)$, $\mathrm{SO}_{4} 94.3 \pm 116.39 \mathrm{ppm}(\mathrm{n}=14), \mathrm{SiO}_{2} 12.9 \pm 16.39 \mathrm{ppm}(\mathrm{n}=14)$.

Inorganic anions in deep sea water; $\mathrm{Cl} 8396.7 \mathrm{ppm}, \mathrm{NO}_{2} 14.2 \mathrm{ppm}, \mathrm{SO}_{4} 2277.7 \mathrm{ppm}$, $\mathrm{SiO}_{2} 6.4 \mathrm{ppm}$.

( 5 ) $\mathrm{K}$-Index and O-Index by Hashimoto in bottled drinking deep sea water; $\mathrm{K}-$ Index $-23.3 \pm 27.33$, O-Index $1.1 \pm 1.55$. Although natural mineral water was classified as having a "good taste" by K-Index and O-Index was $68-76 \%$, that of bottled drinking deep sea water was $14 \%$.

(6) Volatile halogenated hydrocarbons in bottled drinking deep sea water; Total THM 2.7 $\pm 4.93 \mathrm{ppb}(\mathrm{n}=8)$, CF $0.7 \pm 0.47 \mathrm{ppb}(\mathrm{n}=8)$, BDC $0.6 \pm 0.49 \mathrm{ppb}(\mathrm{n}=3)$, DBC $1.6 \pm 1.47 \mathrm{ppb}(\mathrm{n}=3)$, BF $5.4 \pm 4.99 \mathrm{ppb}(\mathrm{n}=3)$. 
Volatile halogenated hydrocarbons in source water; Total THM 0.8ppb, CF $0.7 \mathrm{ppb}$. MCF, TCE and PCE were below the limit of detection.

( 7 ) Microorganism; Five brands of bottled drinking deep sea water and one of the source water showed detection of microorganisms in nutrient agar, but not in TCBS agar or GAM agar.

It was found that bottled drinking deep sea water more contained $\mathrm{Na}, \mathrm{Mg}, \mathrm{K}, \mathrm{Cr}, \mathrm{Zn}$, $\mathrm{Cl}$ ion and $\mathrm{F}$ ion as compared with natural mineral water.

\section{1. 緒言}

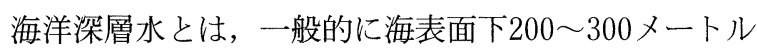
よりも深い海，いわゆる深海にある海水を指し，海洋表 層水と異なり産業廃水や生活排水，そして河川水の影響 をほとんど受けない。さらに太陽光線が届かないため植 物の光合成が行われず，植物性プランクトンの増殖が抑 えられ，清浄性が高くなる。また，植物性のプランクト ンが増殖しないため, 動物性プランクトンの増殖もみら れず，プランクトンの増殖に必要な無機塩が消費されず, 無機富栄養性であるといわれている1),2)。

このような清浄性，無機富栄養性の特性をもった海洋 深層水を原料とした各種加工食品の製造や農産物の栽培, さらに温度差発電などその利用法は多岐に渡っている3)。

一方, 我が国の容器入り飲用水（以下ミネラルウォー タ一類：MW）の消費量の増加は著しく，国内生産量 からみると 1980 年には $78,000 \mathrm{k} l$ であったものが1990年 $150,000 \mathrm{k} l, 2000$ 年 $894,440 \mathrm{k} l, 2003$ 年では $1,132,500 \mathrm{k} l$ となっている。 $\mathrm{MW}$ 類の一人当たりの消費量の推移か らみても1990年から増加し始めているが，その1990年を 基準として現在を比較しても約 8 倍に増加している。容 器入り飲用水の原水は一般に地下水を利用しているが, 最近の海洋深層水を原水とした製品は2003年から生産量 の調査対象となり，その結果 MW 類の総生産量の $2 \%$ におよんでいる4)。

しかしながら海洋深層水を利用した市販の容器入り飲 用海洋深層水（以下，飲用海洋深層水）の性状について は未だ十分に研究されていない。

そこで市場にみられる飲用海洋深層水について，その 性状を知るために製造方法，表示を調査し，むた微量ミ ネラル類を含むミネラル成分，低沸点有機ハロゲン化合 物，微生物について検討したので，その結果について報 告する。

\section{2. 調査および実験方法}

(1) 試 料

我が国の海洋深層水の主な採水場である北海道, 富山 県, 神奈川県, 静岡県, 高知県, 沖縄県およびその他, ハワイの海洋深層水を原水として製造されている飲用海 洋深層水 14 銘柄及び富山県の海洋深層水（以下，原水） の計15種類を調査・分析に用いた。Tab. 1 に試料の概要 を示した。
Table 1 Summary of Sample

\begin{tabular}{clr}
\hline Sample No. & \multicolumn{1}{c}{ Gathered Region } & Volume $(\mathrm{ml})$ \\
\hline 1 & Off Rausu & 500 \\
2 & Off Namerikawa & 2,000 \\
3 & Off Namerikawa & 500 \\
4 & Off Miura & 500 \\
5 & Izu Oshima & 1,500 \\
6 & Off Muroto & 500 \\
7 & Off Muroto & 500 \\
8 & Off Muroto & 500 \\
9 & Off Muroto & 500 \\
10 & Off Muroto & 500 \\
11 & Off Okinawa & 500 \\
12 & Off Kumejima & 500 \\
13 & Hawaiian Island(USA) & 500 \\
14 & Hawaiian Island(USA) & 500 \\
15 & Off Namerikawa & 1,000 \\
\hline
\end{tabular}

No.1-14 : The bottled drinking deep sea water

No.15 : Source water of the bottled drinking deep sea water

\section{(2) 調 査}

飲用海洋深層水の製造方法とその製品表示について調 査した。製造方法についてはパンフレット，インターネ ット，電話により調査した。

\section{(3) 実験方法}

1）ミネラル 日立製 A-2000形原子吸光光度計に て Ca，K，Naを測定した。島津製作所製 ICP-MS 8500型にて $\mathrm{Mg}, \mathrm{Fe}, \mathrm{Cu}, \mathrm{Mn}, \mathrm{Zn}$, Se, P, Li, B, $\mathrm{Al}, \mathrm{Si}, \mathrm{V}, \mathrm{Cr}, \mathrm{Ni}, \mathrm{Ge}, \mathrm{Rb}, \mathrm{Mo}$ を測定した。

2 ) 低沸点有機ハロゲン化合物島津製作所製ガ スクロマトグラフィー GC-148 ECD 検出器により，ク ロロホルム $(\mathrm{CF})$ ，ブロモジクロロメタン $(\mathrm{BDC}), \quad シ ゙$ ブロモクロロメタン ( $\mathrm{DBC})$ ，ブロモホルム $(\mathrm{BF})$, 1,1,1-トリクロロエチレン $(\mathrm{MCF})$, トリクロロエチレ ン $(\mathrm{TCE})$ ，テトラクロロエチレン（PCE）の低沸点有 機ハロゲン化合物を測定した。

3）無機陰イオンダイオネックス社製イオンク ロマトグラフ DX-AQ型によりフッ素イオン $(\mathrm{F})$ ，亜 硝酸イオン $\left(\mathrm{NO}_{2}\right)$ ，硝酸イオン $\left(\mathrm{NO}_{3}\right)$ ，臭素イオン $(\mathrm{Br})$ ，塩素イオン $(\mathrm{Cl})$ ，硫酸イオン $\left(\mathrm{SO}_{4}\right)$ を測定し た。

4 ）水質検査に準じた分析項目 $\mathrm{SiO}_{2}$ はモリブデ ン青法で測定し, 全蒸発残留物, 遊離炭酸, $\mathrm{pH} 4.8$ 総ア 
ルカリ度, 過マンガン酸カリウム消費量は常法5)通り測 定した。

5 ) 硬 度 $\mathrm{Ca}, \mathrm{Mg}$ の含有量 $(\mathrm{mg} / \mathrm{l})$ 加計算 により求めた。

6) $\mathrm{pH} \quad \mathrm{pH}$ は堀場製作所 $\mathrm{pH}$ メーターF-21にて 測定した。

7 ） K-Index および O-Index 橋本ら ${ }^{6)}$ による KIndex と O-Index を分析值から計算により求めた。

8 ）微生物検査微生物検査は普通寒天培地, 生 菌数測定用標準寒天培地, TCBS 培地, GAM 寒天培地 を用いた。すなわち，試料 $100 \mathrm{~m} l$ を濾過したメンブラン フィルターをそれぞれの寒天培地にのせ， $37^{\circ} \mathrm{C} て ゙ 48$ 時間 培養して菌数を求めた。なお，GAM 寒天培地について は嫌気培養を行った。

\section{3. 調査結果}

\section{（1） 容器入り飲用海洋深層水の概要および製造方法}

(1)試料 1 は汲み上げた原水を逆浸透膜法により，分離 した水と濃縮深層水に分離，また，新たな原水をイオン 交換膜電気透析により $\mathrm{Na}$ イオンと $\mathrm{Cl}$ イオンのみを取 り除いたミネラル水をつくり, 逆浸透膜法で作った真水 とブレンド，加熱殺菌して製造。

(2)試料 2 はイオン交換により脱塩を行い製造。

(3)試料 3 は汲み上げた原水を多段式イオン，イオン交 換膜を用いた電気透析法により，Naイオンを分離・濃 縮し，その水をナチュラルミネラルウォーターで飲用可 能な濃度にまで薄めて製造。

(4)試料 4 は脱塩したものを購入して販売しているため, 詳しい製法は不明。
(5)試料 5 は海岸から $200 \mathrm{~m}$ ほどの陸地に地下 $300 \mathrm{~m}$ の 井戸を掘り，汲み上げた水の塩分を除去して製造。

6試料 6，7 は汲久上げた原水を逆浸透膜使用の逆浸 透圧法より，濃縮ミネラル水と水とに分離する。ミネラ ル水は煮沸させて塩分を取り除きながら更に濃縮を行い, 生成したミネラル水を最初に分離した水とブレンドし， 飲用可能な濃度にして製造。

(7)試料 8 は RO システムによる逆漫透膜法により製造。 (8)試料 9，10，11は汲み上げた原水を逆浸透膜法によ り，ミネラル水と水とに分離する。その分離した水にミ ネラル水をブレンドして製造。

(9)試料12は汲み上げた原水を海洋深層水淡水化装置で フィルターを通し，水と濃縮塩水とに分離する。その分 離した水に濃縮塩水から取り出したミネラル分を添加し て製造。

(10)試料13は電気浸透膜法で $\mathrm{Na}$ イオンと $\mathrm{Cl}$ イオンを 取り除いて製造。

(11)試料14は詳細不明。

\section{（2）容器入り飲用海洋深層水の表示}

製品表示については，微量元素含有量としてナトリウ ム, カリウム, マグネシウム, カルシウム, 塩化物イオ ン, 硫酸イオン, 塩素イオンを表示しているものがあり, 微量元素含有量の表示で疑問に思われるものが 3 例めっ た。

\section{4. 分析結果}

容器入り飲用海洋深層水の蒸発残留物, 遊離炭酸, 総 アルカリ度, 硬度, $\mathrm{pH}$, 過マンガン酸カリウム消費量, ミネラル成分, 微量ミネラル, 無機陰イオン, K-Index,

Table 2 Characteristic Value of Bottled Drinking Deep Sea Water

(ppm)

\begin{tabular}{|c|c|c|c|c|c|c|}
\hline Sample & $\begin{array}{l}\text { Residue on } \\
\text { Evaporation }\end{array}$ & $\begin{array}{l}\text { Free carbon } \\
\text { dioxide }\end{array}$ & $\begin{array}{c}\mathrm{pH} 4.8 \\
\text { Alkalinity }\end{array}$ & Hardness* & $\mathrm{pH}$ & $\begin{array}{c}\text { Consumption } \\
\text { of } \mathrm{KMnO}_{4}\end{array}$ \\
\hline 1 & 2,073 & 3.4 & 10 & 1,200 & 7.06 & 2.3 \\
\hline 2 & 509 & 7.0 & 12 & 255 & 6.80 & 0.3 \\
\hline 3 & 504 & 8.0 & 17 & 280 & 6.76 & 1.9 \\
\hline 4 & 517 & 1.9 & 3 & 256 & 7.06 & 0.8 \\
\hline 5 & 476 & 2.3 & 10 & 297 & 7.46 & 1.1 \\
\hline 6 & 515 & 1.8 & 1 & 266 & 6.23 & 0.3 \\
\hline 7 & 1,952 & 2.7 & 2 & 1,114 & 6.33 & 0.5 \\
\hline 8 & 496 & 2.3 & 11 & 67 & 7.17 & 0.9 \\
\hline 9 & 638 & 3.3 & 2 & 299 & 6.65 & 1.5 \\
\hline 10 & 141 & 2.9 & 1 & 12 & 6.67 & 0.4 \\
\hline 11 & 193 & 4.1 & 24 & 261 & 7.68 & 0.5 \\
\hline 12 & 598 & 4.0 & 1 & 293 & 6.00 & 0.6 \\
\hline 13 & 465 & 5.4 & 30 & 207 & 7.16 & 1.0 \\
\hline 14 & 198 & 2.5 & 2 & 4 & 6.35 & 3.1 \\
\hline Ave. & 663 & 3.7 & 8.9 & 344 & 6.81 & 1.1 \\
\hline \pm S.D. & 592.2 & 1.89 & 9.28 & 360.3 & 0.483 & 0.84 \\
\hline \multicolumn{7}{|c|}{ (Source Water) } \\
\hline Sample & $\begin{array}{l}\text { Residue on } \\
\text { Evaporation }\end{array}$ & $\begin{array}{l}\text { Free carbon } \\
\text { dioxide }\end{array}$ & $\begin{array}{c}\mathrm{pH} 4.8 \\
\text { Alkalinity }\end{array}$ & Hardness* & $\mathrm{pH}$ & $\begin{array}{l}\text { Consumption } \\
\text { of } \mathrm{KMnO}_{4}\end{array}$ \\
\hline 15 & 42,723 & 7.5 & 61.1 & $* *$ & 7.4 & 199.6 \\
\hline
\end{tabular}

$*$ : Hardness $=(0.04990 \times \mathrm{Ca}+0.08224 \times \mathrm{Mg}) / 0.02$,

** : Not measured 
O-Index, 微生物検査, 低沸点有機ハロゲン化合物の測 定結果を，微生物を除き Tab.2 に平均值と標準偏差で 示した。

（1）水の特性值（Tab.2）

全蒸発残留物は $663 \pm 592.2 \mathrm{ppm}$ であり，原水では $42,723 \mathrm{ppm}$ であった。遊離炭酸は $3.7 \pm 1.89 \mathrm{ppm}$ であり, 原水では $7.5 \mathrm{ppm}$ であった。総アルカリ度は $8.9 \pm$

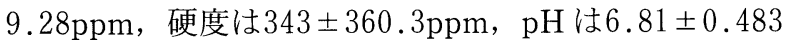
であった。過マンガン酸カリウム消費量は, $1.1 \pm 0.84$ ppm であり，原水では199.6ppm であった。

(2) ミネラル, 微量ミネラル含量 (Tab.3)

$\mathrm{Na} 43.7 \pm 29.21 \mathrm{ppm}, \mathrm{Mg}$ は83.3 $287.42 \mathrm{ppm}, \mathrm{K}$ は10.5 $17.00 \mathrm{ppm}, \mathrm{Ca} 14.7 \pm 17.88 \mathrm{ppm}$ であった。

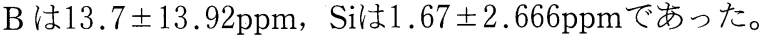

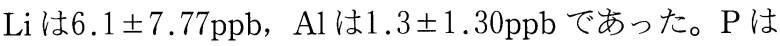
$41.7 \pm 30.57 \mathrm{ppb}, \mathrm{Vは1} 2.5 \pm 7.36 \mathrm{ppb}, \mathrm{Cr} 0.3 \pm$ $0.21 \mathrm{ppb}, \mathrm{Mn} は 1.0 \pm 2.12 \mathrm{ppb}$, Fe は $12.9 \pm 3.64 \mathrm{ppb}$ で

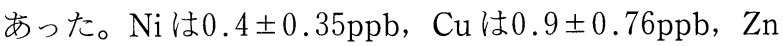

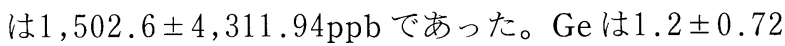
$\mathrm{ppb}, \mathrm{Se} は 2.7 \pm 3.81 \mathrm{ppb}, \mathrm{Rb} 3.6 \pm 4.82 \mathrm{ppb}$, Moは $0.7 \pm 0.71 \mathrm{ppb}$ であった。

(3) 無機陰イオン（Tab.4）

$\mathrm{F}$ イオンは 14 例中 9 例中に検出され $5.4 \pm 8.56 \mathrm{ppm}$, $\mathrm{Cl}$ イオンは14例中全試料に検出され $252.2 \pm 207.55 \mathrm{ppm}$ であった。No.15の原水は8,396.7ppm であった。 $\mathrm{NO}_{2}$ イオンは原水にのみ検出され $14.2 \mathrm{ppm}$ であった。 $\mathrm{Br}$ イ

Table 3 Mineral Content of Bottled Drinking Deep Sea Water

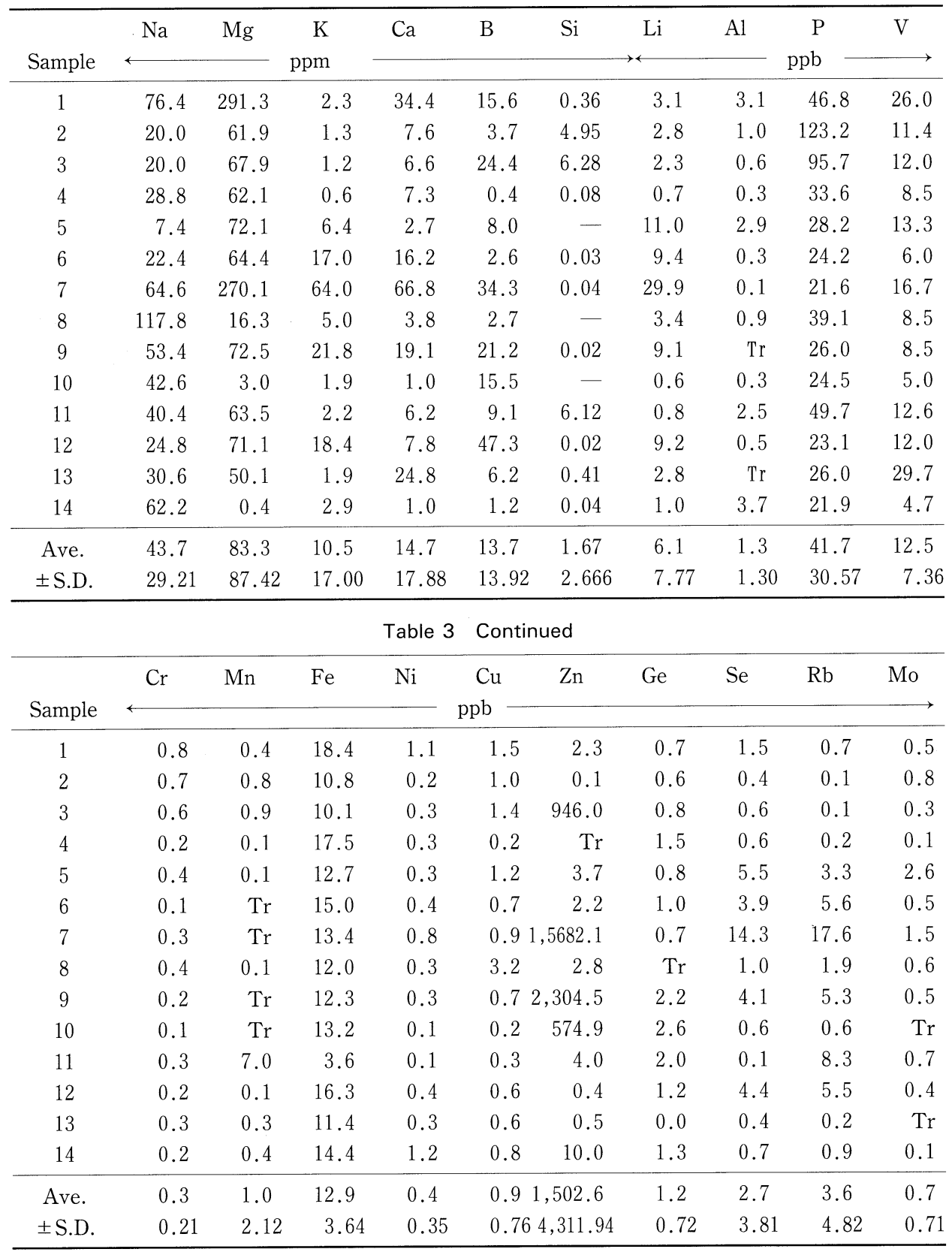

$\operatorname{Tr}:<0.1 \mathrm{ppb}$ 
日本食生活学会誌 Vol.15 No.3（2004）

Table 4 Inorganic Anion of Bottled Drinking Deep Sea Water (ppm)

\begin{tabular}{cccccccc}
\hline Sample & \multicolumn{1}{c}{$\mathrm{F}$} & \multicolumn{1}{c}{$\mathrm{Cl}$} & $\mathrm{NO}_{2}$ & $\mathrm{Br}$ & $\mathrm{NO}_{3}$ & \multicolumn{1}{c}{$\mathrm{SO}_{4}$} & $\mathrm{SiO}_{2}$ \\
\hline 1 & 27.1 & 844.1 & - & - & 1.7 & 203.4 & 2.4 \\
2 & - & 154.3 & - & - & - & 74.6 & 38.6 \\
3 & 0.1 & 233.8 & - & 4.5 & 1.3 & 78.6 & 39.4 \\
4 & 0.8 & 198.8 & - & - & 1.9 & 41.7 & 0.3 \\
5 & 2.5 & 217.9 & - & 3.0 & 0.2 & 10.9 & 10.9 \\
6 & 0.9 & 172.4 & - & - & - & 166.8 & 1.4 \\
7 & 2.3 & 566.8 & - & 4.8 & - & 441.1 & 0.9 \\
8 & 9.1 & 172.4 & - & - & - & 28.8 & 14.3 \\
9 & 1.9 & 265.4 & - & - & - & 116.7 & 1.2 \\
10 & - & 90.0 & - & - & 2.2 & 1.8 & 0.1 \\
11 & - & 73.8 & - & - & 18.0 & 5.8 & 40.9 \\
12 & - & 257.9 & - & 2.3 & 1.6 & 78.6 & 2.4 \\
13 & - & 164.8 & - & - & - & 40.3 & 27.7 \\
14 & 3.9 & 118.0 & - & - & - & 31.3 & 0.1 \\
\hline Ave. & 5.4 & 252.2 & - & 3.7 & 3.8 & 94.3 & 12.9 \\
\pm S.D. & 8.56 & 207.55 & - & 1.19 & 6.28 & 116.39 & 16.39 \\
$\mathrm{n}$ & 9 & 14 & - & 4 & 7 & 14 & 14 \\
\hline (Source Water & & & & & & & $(\mathrm{ppm})$ \\
\hline Sample & $\mathrm{F}$ & $\mathrm{Cl}$ & $\mathrm{NO}_{2}$ & $\mathrm{Br}$ & $\mathrm{NO}_{3}$ & $\mathrm{SO}_{4}$ & $\mathrm{SiO}_{2}$ \\
\hline 15 & 0 & $8,396.7$ & 14.2 & - & - & $2,277.7$ & 6.4 \\
\hline
\end{tabular}

- : Not detected

Table 5 Classification by K-and O-Index, and the Condition of Good Taste Water of Bottled Drinking Deep Sea Water

\begin{tabular}{ccc}
\hline Sample & K-Index* & O-Index** $^{* *}$ \\
\hline 1 & -32.1 & 0.2 \\
2 & -9.8 & 0.4 \\
3 & -10.8 & 0.3 \\
4 & -17.8 & 0.0 \\
5 & -3.7 & 0.3 \\
6 & -3.3 & 1.6 \\
7 & 10.6 & 6.0 \\
8 & -98.7 & 0.7 \\
9 & -27.4 & 2.2 \\
10 & -36.1 & 0.4 \\
11 & -28.9 & 0.8 \\
12 & -13.8 & 1.0 \\
13 & -1.8 & 0.8 \\
14 & -53.1 & 0.1 \\
\hline Ave. & -23.3 & 1.1 \\
\pm S.D. & 27.33 & 1.55 \\
\hline
\end{tabular}

$*: \mathrm{K}-\mathrm{Index}=(\mathrm{Ca}-0.87 \mathrm{Na})$

$* *: \mathrm{O}-\mathrm{Index}=\left(\mathrm{Ca}+\mathrm{K}+\mathrm{SiO}_{2}\right) /\left(\mathrm{Mg}+\mathrm{SO}_{4}\right)$

オンは14例中 4 例について検出され $3.7 \pm 1.19 \mathrm{ppm}$ であ った。 $\mathrm{NO}_{3}$ イオンは14例中 7 例について検出され $3.8 \pm$ $6.28 \mathrm{ppm}$ であった。

$\mathrm{SO}_{4}$ イオンは14例中全試料に検出され $94.3 \pm 116.39$ $\mathrm{ppm}$ であり，原水では2,277.7ppmであった。 $\mathrm{SiO}_{2}$ は 14 例中全試料に検出され $12.9 \pm 16.39 \mathrm{ppm}$ であり，原水 では6.4ppm であった。

（4）水の味（Tab.5）

分析值からおいしさを計算する橋本 6 ( 5 ら 方法に従い，K-Index，O-Index を求めた結 果, K-Indexは-23.3土27.33, O-Index は $1.1 \pm 1.55$ であった。

\section{（5）低沸点有機ハロゲン化合物（Tab.6）}

総トリハロメタン (THM) は 14 試料中 8

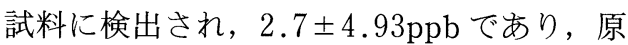
水では $0.8 \mathrm{ppb}$ であった。THMのなかでク ロロホルム $(\mathrm{CF})$ は 8 試料に検出され $0.7 \pm$ $0.47 \mathrm{ppb}$ であった。原水では $0.7 \mathrm{ppb}$ であっ た。ブロモジクロロメタン（BDC）は 3 試 料に検出され $0.6 \pm 0.49 \mathrm{ppb}$ ，ジブロモクロ ロメタン $(\mathrm{DBC})$ は 3 試料に検出され $1.6 \pm$ $1.47 \mathrm{ppb，ブロモホルム（BF）は} 3$ 試料に 検出され $5.4 \pm 4.99 \mathrm{ppb}$ であった。

$1,1,1$-トリクロロエチレン $(\mathrm{MCF})$, トリ クロロエチレン (TCE)，テトラクロロエチ レン（PCE）は，未検出または検出限界以 下であった。

総低沸点有機ハロゲン化合物（VHHs）は $2.7 \pm 4.98 \mathrm{ppb}$ であった。

（6）飲用海洋深層水の微生物検査（Tab.7）

TCBS 培地, GAM 寒天培地では菌は検出されなかっ た。しかし, 普通寒天培地では No. 3，4，7，12，14 の 5 試料と原水で, また生菌数測定用普通寒天培地では No. 4 につき菌が検出された。

普通寒天培地では試料 3 と原水で検出された菌の判定 を行ったところグラム陰性桿菌であると判定した。また No. 4，7，12，14で検出された菌の判定を行ったとこ ろグラム陽性球菌であると判定した。

生菌数測定用普通寒天培地ではNo.15で検出された菌 の種類につき判定を行ったところグラム陽性球菌である と判定した。

Tab.8 に飲用海洋深層水の細菌数を示した。すなわち 飲用海洋深層水の細菌数は $100 \mathrm{~m} l$ 中, No. 3 で 8 個, No. 4 で13個, No. 7 で 9 個, No.12 8 個, No.14で 1 個, 原水では $2.98 \times 102$ 個であった。

\section{5. 考察}

（1）容器入り飲用海洋深層水の製造方法

製造方法の大部分は逆浸透膜法を利用した脱塩を行い 逆浸透膜法により分離した水とミネラル水に分離し, ミ ネラル水の一部を飲用可能になるように分離した水で希 釈し, 製造していた。なた，電気透析法を使用している メーカーもあった。

\section{（2）表示量に対する分析平均値との比較}

主要なミネラルである $\mathrm{Na}, \mathrm{Mg}, \mathrm{K}, \mathrm{Ca}$ について表 示量を 100 として分析平均值の割合を求め, 比較すると 
容器入り飲用海洋深層水の性状について

Table 6 Volatile Halogenated Hydrocarbon of Bottled Drinking Deep Sea Water $(\mathrm{ppb})$

\begin{tabular}{|c|c|c|c|c|c|c|c|c|c|}
\hline Sample & $\mathrm{CF}$ & $\begin{array}{l}\text { THM* } \\
\text { BDC }\end{array}$ & $\mathrm{DBC}$ & $\mathrm{BF}$ & $\begin{array}{l}\text { Total } \\
\text { THM }\end{array}$ & $\mathrm{MCF}$ & $\begin{array}{l}\text { VHHs** } \\
\text { TCE }\end{array}$ & $\mathrm{PCE}$ & $\begin{array}{c}\text { Total } \\
\text { VHHs }\end{array}$ \\
\hline 1 & 0.3 & 0.2 & 0.4 & 0.5 & 1.3 & - & - & - & 1.3 \\
\hline 2 & 0.5 & $\operatorname{Tr}$ & - & - & 0.5 & - & - & - & 0.5 \\
\hline 3 & $\operatorname{Tr}$ & $\operatorname{Tr}$ & - & - & $\operatorname{Tr}$ & - & - & - & $\operatorname{Tr}$ \\
\hline 4 & 0.7 & $\operatorname{Tr}$ & $\operatorname{Tr}$ & - & 0.7 & - & - & - & 0.7 \\
\hline 5 & 1.7 & 1.1 & 1.1 & 5.3 & 2.3 & - & - & - & 2.3 \\
\hline 6 & 0.7 & $\operatorname{Tr}$ & $\operatorname{Tr}$ & - & 0.7 & - & - & - & 0.7 \\
\hline 7 & $\operatorname{Tr}$ & - & - & - & $\operatorname{Tr}$ & - & - & - & $\operatorname{Tr}$ \\
\hline 8 & $\operatorname{Tr}$ & - & $\operatorname{Tr}$ & - & $\operatorname{Tr}$ & - & - & - & $\operatorname{Tr}$ \\
\hline 9 & $\operatorname{Tr}$ & $\operatorname{Tr}$ & $\operatorname{Tr}$ & - & $\operatorname{Tr}$ & - & - & - & $\operatorname{Tr}$ \\
\hline 10 & 1.0 & $\operatorname{Tr}$ & - & - & 1.0 & - & - & - & 1.0 \\
\hline 11 & $\operatorname{Tr}$ & - & - & - & $\operatorname{Tr}$ & - & - & - & $\operatorname{Tr}$ \\
\hline 12 & 0.2 & $\operatorname{Tr}$ & $\operatorname{Tr}$ & - & 0.2 & - & - & - & 0.2 \\
\hline 13 & $\operatorname{Tr}$ & - & - & - & $\operatorname{Tr}$ & $\operatorname{Tr}$ & - & - & $\operatorname{Tr}$ \\
\hline 14 & 0.8 & 0.4 & 3.2 & 10.4 & 14.8 & - & - & - & 14.8 \\
\hline Ave. & 0.7 & 0.6 & 1.6 & 5.4 & 2.7 & - & - & - & 2.7 \\
\hline \pm S.D. & 0.47 & 0.49 & 1.47 & 4.99 & 4.93 & - & - & - & 4.93 \\
\hline $\mathrm{n}$ & 8 & 3 & 3 & 3 & 8 & - & - & - & 8 \\
\hline \multicolumn{10}{|c|}{ (Source Water) } \\
\hline Sample & $\mathrm{CF}$ & $\begin{array}{l}\text { THM* } \\
\text { BDC }\end{array}$ & $\mathrm{DBC}$ & $\mathrm{BF}$ & $\begin{array}{l}\text { Total } \\
\text { THM }\end{array}$ & $\mathrm{MCF}$ & $\begin{array}{l}\mathrm{VHHs}^{* *} \\
\text { TCE }\end{array}$ & PCE & $\begin{array}{l}\text { Total } \\
\text { VHHs }\end{array}$ \\
\hline 15 & 0.7 & 0.1 & $\operatorname{Tr}$ & - & 0.8 & - & - & - & 0.8 \\
\hline
\end{tabular}

CF : Chloroform BDC : Bromodichloromethane DBC : Dibromochloromethane BF : Bromoform MCF : 1,1,1-Trichloroethane TCE : Trichloroethylene PCE : Tetrachloroethylene

* : Trihalomethane **: Volatile halogenated Hydrocarbons

$\operatorname{Tr}: \mathrm{CF} \leqq 0.2 \mathrm{ppb}, \quad \mathrm{BDC} \leqq 0.05 \mathrm{ppb}, \quad \mathrm{DBC} \leqq 0.08 \mathrm{ppb}, \mathrm{BF} \leqq 0.4 \mathrm{ppb} \quad-$ : Below limited of detection

Table 7 Microorganism in Bottled Drinking Deep Sea Water

\begin{tabular}{c|cccc}
\hline Sample & Nutrient Agar & Standard Nutrient Agar & TCBS Agar & GAM Agar \\
\hline 1 & - & - & - & - \\
2 & - & - & - & - \\
3 & + & - & - & - \\
4 & + & + & - & - \\
5 & - & - & - & - \\
6 & - & - & - & - \\
7 & + & - & - & - \\
8 & - & - & - & - \\
9 & - & - & - & - \\
10 & - & - & - & - \\
11 & - & - & TCBS Agar & GAM Agar \\
12 & + & - & - & - \\
13 & + & - & & - \\
14 & & & & - \\
\hline
\end{tabular}


Table 8 Total Viable Count of Bottled Drinking Deep Sea Water

\begin{tabular}{|c|c|}
\hline Sample & Count $\left(\mathrm{CFU}^{*} / 100 \mathrm{~m} l\right)$ \\
\hline 1 & - \\
\hline 2 & - \\
\hline 3 & 8 \\
\hline 4 & 13 \\
\hline 5 & - \\
\hline 6 & - \\
\hline 7 & 9 \\
\hline 8 & - \\
\hline 9 & - \\
\hline 10 & - \\
\hline 11 & - \\
\hline 12 & 8 \\
\hline 13 & - \\
\hline 14 & 1 \\
\hline \multicolumn{2}{|c|}{ (Source Water) } \\
\hline Sample & Count $\left(\mathrm{CFU}^{*} / 100 \mathrm{~m} l\right)$ \\
\hline 15 & $2.98 \times 10^{2}$ \\
\hline
\end{tabular}

$\mathrm{Na}$ では平均值 $100 \%$ ，最小值 $16 \%$ ，最大值 $353 \%$ で分析 平均值と表示值はほぼ一致していたが，バラツキが見ら れた。 $\mathrm{Mg}$ は平均值 $113 \%$, 最小值 $8 \%$, 最大值 $238 \%$ で 分析平均值とほぼ一致していたが，バラツキがみられた。 $\mathrm{K}$ は平均值 $95 \%$, 最小値 $20 \%$, 最大值 $140 \%$ で分析平均 值とほぼ一致していたが，バラツキが見られた。Ca は 平均值 $60 \%$, 最小值 $12 \%$, 最大值 $96 \%$ で分析平均值と表 示値に大きな差が見られた。

以上表示については，分析值との間にバラツキがみら れ，表示值の再検討が必要であると考えられた。

(3) 容器入り飲用海洋深層水之市販の容器入り飲用水之 の比較

飲用海洋深層水の分析結果と著者らが報告した国産 MW 類259銘柄の分析結果7,8) それぞれの平均值で比 較検討した。

$\mathrm{Na}$ は MW 類の約 3 倍高く, 海水を原料としている 特徵と考えられる。 $\mathrm{Mg}$ は $\mathrm{MW}$ 類の約 20 倍, $\mathrm{K}$ は約 8 倍，Zn は約50倍高く，また Se は MW 類の1/40 と低 かった。これらは飲用海洋深層水の大きな特徵であると 考えられる。

$\mathrm{Ca}, \mathrm{Fe}$ はいずれも $\mathrm{MW}$ と大差は見られず，P と $\mathrm{Al}$ は $\mathrm{MW}$ 類の約 1/3，B と Mn は MW と大差はなく, Moは MW 類の約 1 / 9 であった。Cr は MW 類の約 9 倍であった。

遊離炭酸は $\mathrm{MW}$ 類と差がないが，総アルカリ度は $\mathrm{MW}$ 類の $1 / 5$ であり, 飲用海洋深層水の特徵と考えら れる。硬度は $\mathrm{MW}$ 類の約 5 倍であった。 $\mathrm{pH}$ は $\mathrm{MW}$ 類 よりやや低い值を示した。

以上, 海洋深層水を原料とする容器入り飲料水は $\mathrm{Na}$,
$\mathrm{Mg}, \mathrm{K}, \mathrm{Cr}, \mathrm{Zn}, \mathrm{Cl}$ イオン, $\mathrm{F}$ イオンの含有量が地下 水を原料とする $\mathrm{MW}$ 類より多いことが判明した。しか し, Se Poが少なったが，その理由については不明 である。

美味しい水研究会9)の美味しい水の水質要件は「蒸発 残留物 $30 \sim 200 \mathrm{mg} / l$, 硬度 $10 \sim 100 \mathrm{mg} / l$, 遊離炭酸 $3 \sim$ $30 \mathrm{mg} / l$, 過マンガン酸カリウム $3 \mathrm{mg} / l$ 以下」とされて いるが, 今回の飲用海洋深層水の水質要件に適合するも のは見られなかった。

橋本ら ${ }^{6)}$ の方法により飲用海洋深層水を, ミネラルの 分析結果から K-Index と O-Index を求めた。美味しい 水の場合は $\mathrm{K}<5.2, \mathrm{O} \geqq 2$, 美味しくて健康な水の場 合は $\mathrm{K} \geqq 5.2, \mathrm{O} \geqq 2$, 健康な水の場合は $\mathrm{K} \geqq 5.2, \mathrm{O}<$ 2 , いずれにも属さない水の場合は $\mathrm{K}<5.2, \mathrm{O}<2$ と する方法に従い水の美味しさの分類を行った。

14例中美味しい水に適合したものが No. 9 の 1 例, 美 味しくて健康な水に適合したものはNo. 2 の 1 例で美味 しい水に属するものは 2 例の $14 \%$ のみで，いずれにも属 さない水が14例中 $86 \%$ であったこれに対し MW 類は 種類によって異なるが 68 ～76\%が美味しい水になる7),8)。 （4）容器入り飲用海洋深層水の衛生状態

$\mathrm{F}$ イオンは $\mathrm{MW}$ 類の約 15 倍, $\mathrm{Cl}$ イオンは約 30 倍と高 く, これらは飲用海洋深層水の特徵を示すと考えられる。 $\mathrm{NO}_{3}$ イオンは飲用海洋深層水が $\mathrm{MW}$ 類の $1 / 2, \mathrm{SO}_{4}$ は, MW 類と大差はなかった。

低沸点有機ハロゲン化合物において, 検出された試料 中の平均值と $\mathrm{MW}$ 類の平均值 ${ }^{10)}$ と比較すると, $\mathrm{THM}$ の中で $\mathrm{CF}$ は $1 / 7, \mathrm{BDC}$ は $1 / 5, \mathrm{DBC}$ は $1 / 20, \mathrm{BF}$ は約 1 / 6 といずれも低い値であった。

水道水質基準における $\mathrm{NO}_{2}$ 及び $\mathrm{NO}_{3}$, 低沸点有機八 ロゲン化合物である THM, CF, BDC, DBC, BF， TCE, PCEは, 飲用海洋深層水では基準值を越えるも のはなく，また MW 類と比較しても含有量は少なかっ た。しかし，低沸点有機ハロゲン化合物は本来自然界に 見られないことから考えると，これらの物質による環境 污染が進行している可能性が示唆される。

細菌数は一般細菌 100 個 $/ \mathrm{m} l$ 以下とされているが，飲 用海洋深層水では 14 例中 5 例で $1 \sim 13 / 100 \mathrm{~m} l$, 海洋深 層水では $2.98 \times 10^{2} / 100 \mathrm{~m} l$ が検出されたが規制值を越え るものはなかった。

水質管理設定目標では過マンガン酸カリウム消費量は $3 \mathrm{ppm}$ 以下とされているが, 飲用海洋深層水には 3 ppm を越えるものが14例中 1 例存在していた。

\section{6. 要 約}

容器入り飲用海洋深層水 14 種類と原水 1 種類の計 15 種 類の一般性状と食品衛生学的性状を検討した。飲用海洋 深層水については製造方法とその表示調査を行った。

（1）製造方法はほとんど逆浸透圧法であった。

（2）飲用海洋深層水の一般性状は全蒸発残留物 $663 \pm$ 
$592.2 \mathrm{ppm}$, 遊離炭酸 $3.7 \pm 1.89 \mathrm{ppm}$, 総アルカリ度 8.9 $\pm 9.28 \mathrm{ppm}$, 硬度 $344 \pm 360.3 \mathrm{ppm}, \mathrm{pH} 6.81 \pm 0.483$, 過 マンガン酸カリウム消費量 $1.1 \pm 0.84 \mathrm{ppm}$ であった。

(3) 飲用海洋深層水のミネラル成分は $\mathrm{Na} 43.7 \pm$ $29.21 \mathrm{ppm}, \mathrm{Mg} 83.3 \pm 87.42 \mathrm{ppm}, \mathrm{K} 10.5 \pm 17.00 \mathrm{ppm}$, Ca $14.7 \pm 17.88 \mathrm{ppm}$, B $13.7 \pm 13.92 \mathrm{ppm}$, Li $6.1 \pm$ $7.77 \mathrm{ppb}, \mathrm{Al} 1.3 \pm 1.30 \mathrm{ppb}$, Si $1.67 \pm 2.666 \mathrm{ppm}, \mathrm{P} 41.7$ $\pm 30.57 \mathrm{ppb}, \mathrm{V} 12.5 \pm 7.36 \mathrm{ppb}$, Cr $0.3 \pm 0.21 \mathrm{ppb}$, Mn $1.0 \pm 2.12 \mathrm{ppb}$, Fe $12.9 \pm 3.64 \mathrm{ppb}$, Ni $0.4 \pm 0.35 \mathrm{ppb}$,

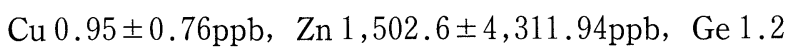
$\pm 0.72 \mathrm{ppb}$, Se $2.7 \pm 3.81$, Rb $3.6 \pm 4.82 \mathrm{ppb}$, Mo 0.7 $\pm 0.71 \mathrm{ppb}$ であった。

（4）無機陰イオンについては飲用海洋深層水では F $5.4 \pm 8.56 \mathrm{ppm}, \mathrm{Cl} 252.2 \pm 207.55 \mathrm{ppm}, \operatorname{Br} 3.7 \pm 1.19$ $\mathrm{ppm}, \mathrm{NO}_{3} 3.8 \pm 6.28 \mathrm{ppm}, \mathrm{SO}_{4} 94.3 \pm 116.39 \mathrm{ppm}$, $\mathrm{SiO}_{2} 12.9 \pm 16.39 \mathrm{ppm}$ であり, 原水では $\mathrm{Cl} \quad 8,396.7$ ppm, $\mathrm{NO}_{2} 14.2 \mathrm{ppm}, \mathrm{SO}_{4} 2,277.7 \mathrm{ppm}, \mathrm{SiO}_{2} 6.4 \mathrm{ppm}$ であった。

（5）飲用海洋深層水の抢いしい水の指標は K-Index

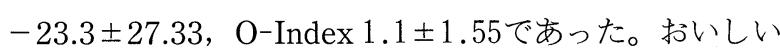
水に分類される割合は MW 類には68～76\%であるのに

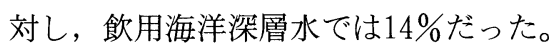

（6）低沸点有機ハロゲン化合物は飲用海洋深層水では 総 THM 2.7 4 4.93ppbであり，その内 CF $0.7 \pm 0.47$ ppb, BDC 0.6 $\pm 0.49 \mathrm{ppb}$, DBC $1.6 \pm 1.47 \mathrm{ppb}$, BF 5.4 $\pm 4.99 \mathrm{ppb}$ であった。原水は総 THM $0.8 \mathrm{ppb}$ であり, その内 $\mathrm{CF}$ は $0.7 \mathrm{ppb}$ であった。飲用海洋深層水, 原水 いずれも MCF，TCE，PCEは検出限界以下であった。
（7）微生物検査については普通寒天培地では 5 試料の 飲用海洋深層水と 1 試料の原水に菌が検出された。 TCBS 培地, GAM 寒天培地で検出される菌はなかった。 容器入り飲用海洋深層水は容器入り飲用水（ナチュラ ルミネラルウォーター) に比べ, $\mathrm{Na}, \mathrm{Mg}, \mathrm{K}, \mathrm{Cr}, \mathrm{Zn}$, $\mathrm{Cl}$ イオンおよび $\mathrm{F}$ イオンが多く含まれていた。

終わりに微生物検査をおこなうにあたり，ご指導いた だきました聖徳大学植木幸英教授, 実験にご協力いただ いた望月雅栄さんに感謝申し上げをす。

\section{文献}

1）東京理科大学特別教室 : 水の惑星に住む一人と水との関 わり一 (2001)

2）ニュートン編集部：ニュートン 12月号，98１05（2001）

3）二ュートン編集部：ニュートン８月号，94１01（2002）

4）日本ミネラウォーター協会 : 2003年（1～12月）ミネラ ルウォーター数量調査資料（2004）

5）日本分析化学会北海道支部編：水の分析 第 3 版 化学 同人, $179 \sim 245$ (2002)

6) Susumu Hashimoto, Masanori Fujita, Kenji Furukawa: $J$. of Ferment. Technology, 65, 185 (1987)

7） Tatsuyuki Sugahara：女子栄養大学紀要（英文） 30,15 (1999)

8）菅原龍幸, 崔 榮美, 佐々木弘子：日本食生活学会誌, 11 (1), 34 (2000)

9）扔いしい水研究会：水道協会誌，54，76（1985）

10）菅原龍幸, 川井英雄 : 空気調和 - 衛生工学, 70 (1), 37 (1996) 